$\underline{\text { Research Article }}$

\title{
REFRACTIVE ERRORS AMONG NIGERIAN YOUTHS
}

\author{
AGUWA US ${ }^{1 *}$, OVIE FO ${ }^{1,2}$, ONOIKHUA EE ${ }^{3}$, OLU SI ${ }^{2}$
}

${ }^{1}$ Department of Human Anatomy, Faculty of Basic Medical Sciences, Nnamdi Azikiwe University, Nnewi Campus. ${ }^{2}$ Department of Human Anatomy, Faculty of Basic Medical Sciences, Madonna University Nigeria. ${ }^{3}$ Department of Optometry, Faculty of Health Sciences, Madonna University Nigeria. Email: us.aguwa@unizik.edu.ng

\section{ABSTRACT}

Genetic, cultural, and environmental factors play key roles in the prevalence and distribution of refractive errors. More youths in Nigeria today use medicated glasses to enhance vision than we had in the past decades. This study is aimed at revealing the prevalence of refractive errors among students of Madonna University Nigeria, Elele campus, Rivers state. One thousand questionnaires were randomly distributed to the $3^{\text {rd }}$ year undergraduate students in various departments in the College of Medicine, including anatomy, physiology, medical laboratory science, optometry, public health, and pharmacy. Eight hundred and fifty-two (85.2\%) out of the 1000 of the questionnaires shared were retrieved and analyzed using simple percentages. Data collected included information on age, sex, state of origin, place of residence, and presence of refractive errors. Our results reveal that the incidence of refractive errors was highest in the North-west region of the country having (93.55\%). This was followed by South-west (50.51\%), South-south (32.88\%), South-east (27.67\%), North-central (18.03\%), and North-east (15.79\%). The highest occurring refractive error among the six geopolitical regions of Nigeria is myopia (54\%), followed by hyperopia (21.01\%), astigmatism (15.30\%), and presbyopia (9.46\%). This work represents the first attempt at having a comprehensive outlook at the statistics of refractive errors among Nigerian youths from across the country.

Keywords: Refractive errors, Myopia, Hyperopia, Astigmatism, Presbyopia.

(C) 2020 The Authors. Published by Innovare Academic Sciences Pvt Ltd. This is an open access article under the CC BY license (http://creativecommons org/licenses/by/4. 0/) DOI: http://dx.doi.org/10.22159/ijms.2020.v8i3.36275

\section{INTRODUCTION}

The rate at which younger people below the age of 50 years use medicated glasses today in our society is alarming. Conventionally, we associate poor eyesight with aging; hence, it looks normal when elderly persons use medicated glasses to support their failing eyesight. However, when a good population of teens and youths wear medicated glasses, it is a pointer to the possibility of rising incidence of refractive errors in the population. This study provides data on the incidence of refractive errors among Nigerian youths. Recent studies done among children and young adults show that refractive error has been the most prevalent ocular morbidity despite being to a very large extent correctable (Vinay and Shruthi, 2016; Prakash et al., 2015). Refractive errors vary over age, gender, race and ethnicity, level of education, social class, and degree of urbanization [3].

Reports show that 2.3 billion people worldwide have refractive errors, out of which about 500 million people mostly in developing countries have no access to proper checkup and correction. This has resulted mostly in either blindness or impaired vision [4]. In Pakistan, $11.4 \%$ of the blindness is due to uncorrected refractive errors (National Committee for Prevention of Blindness, Ministry of Health 1994-98; P. 24). Studies indicate that refractive errors are mainly caused by genetic factors, while others suggest interplay between genetics and environmental factors [6]. Apart from a positive history of wearing glasses in the family, environmental factors may include close work or near activity such as prolonged study hours and watching computers/television $[8,10]$.

Tebepa [2] reported 26\% prevalence of refractive errors in Port Harcourt, Ayed et al. found refractive errors in schoolchildren to be $57.2 \%$ in a community in Tunisia 3 , while Chuka-Okosa reported $1.97 \%$ prevalence of refractive errors among students of post primary institution in a rural community in Southeastern Nigeria [4]. Askira [13] reported refractive errors of $31.8 \%$ in Obafemi Awolowo University Teaching Hospital. These widely differing reports on prevalence of refractive errors may be due to difference in sample size and the nature of the population studied.
Myopia, the most studied refractive error, is emerging as a global health problem, due to the costs associated with correction, and its associated pathology such as retinal tears, retinal detachments, and macular degeneration [5]. The prevalence of myopia varies in different parts of the world, being more prevalent in industrialized countries and cities compared to rural areas (Uzma, et al., 2009). Other studies have found an association between socioeconomic status, education, academic achievement, and myopia (Teasdale and Goldschmidt, 1988; Rosner and Belkin, 1987; Parssinen, 1987). In the US, the prevalence of myopia for people between the ages of 12 and 54 surged from $25 \%$ in the early 1970 s to $42 \%$ by 2000 [10]. In Taiwan and Singapore, myopia is found in approximately $30 \%$ of all children 6 and 7 years old and increases to $80 \%$ in young adults [10]. The rapid increase in the prevalence of myopia strongly suggests that environmental factors are having a considerable influence on the development of myopia not explainable by the genetic model (Saw et al., 1996; Mutti et al., 1996).

The prevalence of myopia is about $20 \%$ in the United States [5,6]. In Sumatra, Indonesia Saw et al. [7] reported $26.1 \%$ prevalence of myopia while Raju et al. [8] in India reported 26.99\%. Askira [13] reported $21.1 \%$ and Adegbehingbe et al. [9] reported myopia as the most common spherical error constituting $22.7 \%$ of their series in a study on the pattern of refractive errors at Obafemi Awolowo University Teaching Hospital, Ile-Ife, in the western part of Nigeria. The prevalence of myopia is about $20 \%$ in the United States, but varies with age, sex, race, ethnicity, occupation, environment, and other factors in various sampled populations [5,6]. In Sumatra, Indonesia Saw et al. [7] reported $26.1 \%$ prevalence of myopia while Raju et al. [8] in India reported $26.99 \%$. Adegbehingbe et al. [9] reported myopia as the most common spherical error constituting $22.7 \%$ of their series in a study on the pattern of refractive errors at Obafemi Awolowo University Teaching Hospital, Ile-Ife, Nigeria.

Myopic youths tend to be bookworms and introverts which could be as a result of the inability to see properly at far distances thereby 
making near work a favorable and safer routine. Hyperopia has usually been found to be less prevalent than myopia among youths. This could be as a result of the still high accommodative state present in youths which compensate for any latent hyperopia (Megbelayin et al., 2014). Although in young children, hyperopia and astigmatism may be found to be higher than myopia (Jimenez et al., 2012, Krishnamurthy et al., 2014).

In young children, hyperopia and astigmatism may be found to be higher than myopia (Jimenez et al., 2012, Krishnamurthy et al., 2014). Hypermetropia is considered to be the most common refractive error in infants. Faderin [10] reported hypermetropia constituting $52.2 \%$ of refractive errors in primary schoolchildren in Nigeria while Montes- Mico [11] reported $35.6 \%$ prevalence of hypermetropia in Spain. In a survey of the prevalence of refractive errors among children in lower primary school in Kampala district, Kawuma [12] reported astigmatism as the most common single refractive error accounting for $52 \%$ of all errors of refraction while Adegbehingbe [9] reported 52.8 in Ile-Ife, Nigeria, Askira [13] reported $22.9 \%$ while Presbyopia accounted for $51.3 \%$ of patients with refractive errors.

Table 1: Incidence of refractive errors across the regions of Nigeria

\begin{tabular}{llll}
\hline Region & $\begin{array}{l}\text { Total } \\
\text { respondents }\end{array}$ & $\begin{array}{l}\text { Number using } \\
\text { medicated glasses }\end{array}$ & Percentage \\
\hline North-west & 31 & 19 & 61.29 \\
South-west & 97 & 49 & 50.51 \\
South-south & 295 & 97 & 32.88 \\
South-east & 300 & 83 & 27.67 \\
North-central & 122 & 22 & 18.03 \\
North-east & 19 & 3 & 15.79 \\
\hline
\end{tabular}

Table 2: Distribution of refractive error cases

\begin{tabular}{llll}
\hline S. No. & Refractive error & $\mathbf{n}$ & Percentage \\
\hline 1. & Myopia & 148 & 54.21 \\
2. & Hypermetropia & 77 & 28.21 \\
3. & Presbyopia & 5 & 1.83 \\
4. & Astigmatism & 43 & 15.75 \\
& Total & 273 & 100 \\
\hline
\end{tabular}

Table 3: Distribution of refractive errors across the regions of Nigeria

\begin{tabular}{lllllllll}
\hline & $\mathbf{n}$ & $\mathbf{\%}$ & $\mathbf{n}$ & $\mathbf{\%}$ & $\mathbf{n}$ & $\mathbf{\%}$ & $\mathbf{n}$ & $\mathbf{\%}$ \\
\hline South-east & 47 & 31.76 & 21 & 27.27 & 1 & 20.00 & 11 & 25.58 \\
South-south & 52 & 35.13 & 33 & 42.86 & 0 & 0.00 & 9 & 20.93 \\
South-west & 27 & 18.24 & 7 & 9.09 & 2 & 40.00 & 11 & 25.58 \\
North-east & 3 & 2.03 & 0 & 0.00 & 0 & 0.00 & 0 & 0.00 \\
North-central & 11 & 7.43 & 9 & 11.69 & 1 & 20.00 & 5 & 11.63 \\
North-west & 8 & 5.41 & 7 & 9.09 & 1 & 20.00 & 7 & 16.28 \\
Total & 148 & 100 & 77 & 100 & 5 & 100 & 43 & 100 \\
\hline
\end{tabular}

\section{METHODS}

This study was carried out among the $2^{\text {nd }}$ year students of Madonna University Nigeria, Elele campus.

This population was chosen to ensure that whatever visual problems seen were not acquired within the period as a student but was already present before the individual came into the school. This was also ensured further using only respondents who have used medicated glasses for at least 5 years. Meaning that usage must have commenced before studentship. One thousand questionnaires were randomly distributed to undergraduate students in various departments in the College of Medicine, including anatomy, physiology, medical laboratory science, optometry, public health, and pharmacy. Furthermore, our distribution of students according to the states of Nigeria is based on residency, not place of origin. As such, this work leans moretoward environmental rather than genetic causes. Future analysis will consider the genetic factors. Nine hundred and thirty of these questionnaires were retrieved (93\%). Out of that number, $864(86.4 \%)$ met with the conditions stated above and were used for the study. The remaining 66 were discarded. Data were analyzed using simple percentages. Data collected included information on age, sex, state of origin, place of residence with duration, and presence of refractive errors.

\section{RESULTS}

Table 1 shows that the incidence of use of refractive North-west and South-west had the highest incidences of refractive errors with $61.29 \%$ and $50.51 \%$, respectively. North-east and North-central had the least incidences with $15.79 \%$ and $18.03 \%$, respectively.

From Table 2, myopia had the highest occurrence with $54.21 \%$ of all cases, followed by hypermetropia (28.21\%), astigmatism (15.75\%), and presbyopia $(1.83 \%)$.

Table 3 shows the distribution of refractive errors across the six geopolitical zones of the country. Myopia was highest in South-south and least in North-east. South-east and South-west had high values. Hypermetropia was also highest in South-south followed by South-east and North-central. It was lowest South-west and North-west.

Table 4 shows the frequency of myopia according to individual states of Nigeria. This frequency, however, only represents a direct numerical counting, comparing a state with the total number of cases. So as expected, states in the south will have more frequency than those in the north as the university is located in Rivers state, South-south part of the country.

Table 5 shows the frequency of hypermetropia by states. As in above, states in the southern part of the country had the highest frequency by number.

Table 6 shows the distribution of presbyopia according to states where cases were recorded in our work.

Table 4: Distribution of myopia according to states in Nigeria

\begin{tabular}{llllllll}
\hline S. No. & State & Number & Percentage & S. No. & State & Number & Percentage \\
\hline 1. & Rivers & 27 & 18.12 & 11. & Ondo & 3 & 2.01 \\
2. & Lagos & 22 & 14.80 & 12. & Osun & 2 & 1.34 \\
3. & Delta & 21 & 14.10 & 13. & Bauchi & 2 & 1.34 \\
4. & Anambra & 15 & 10.10 & 14. & Kano & 2 & 1.34 \\
5. & Imo & 12 & 8.05 & 15. & Ebonyi & & 0.67 \\
6. & Enugu & 11 & 7.38 & 16. & Oyo & & 0.67 \\
7. & Abia & 9 & 6.04 & 17. & Borno & & 0.67 \\
8. & FCT & 8 & 5.37 & 18. & Kogi & & 0.67 \\
9. & Cross River & 5 & 3.36 & 19. & Sokoto & & 0.67 \\
10. & Kaduna & 4 & 2.68 & 20. & Katsina & Total & 149 \\
\end{tabular}


Table 5: Distribution of hypermetropia according to states in Nigeria

\begin{tabular}{|c|c|c|c|c|c|c|c|}
\hline S. No. & State & Number & Percentage & S. No. & State & Number & Percentage \\
\hline 1. & Rivers & 19 & 24.67 & 10. & Kogi & 2 & 2.60 \\
\hline 2. & Delta & 8 & 10.40 & 11. & Kano & 2 & 2.60 \\
\hline 3. & Imo & 7 & 9.09 & 12. & Cross River & & 1.30 \\
\hline 4. & Anambra & 6 & 7.79 & 13. & Sokoto & & 1.30 \\
\hline 5. & Edo & 6 & 7.79 & 14. & Plateau & & 1.30 \\
\hline 6. & Lagos & 6 & 7.79 & 15. & Kaduna & & 1.30 \\
\hline 7. & FCT & 6 & 7.79 & 16. & Niger & & 1.30 \\
\hline \multirow[t]{2}{*}{9.} & Enugu & 4 & 5.19 & & & & \\
\hline & & & & & Total & 77 & $100 \%$ \\
\hline
\end{tabular}

Table 6: Distribution of presbyopia according to states in Nigeria

\begin{tabular}{llll}
\hline S. No. & State & Number & Percentage \\
\hline 1. & Lagos & 2 & 50 \\
2. & Anambra & 1 & 25 \\
3. & FCT & 1 & 25 \\
& Total & 4 & 100 \\
\hline
\end{tabular}

Table 7: Distribution of astigmatism according to states in Nigeria

\begin{tabular}{|c|c|c|c|c|c|c|c|}
\hline S. No. & State & Number & Percentage & S. No. & State & Number & Percentage \\
\hline 1. & Lagos & 11 & 25.58 & 8. & Katsina & 2 & 2.33 \\
\hline 2. & Imo & 7 & 16.28 & 9. & Abia & & 2.33 \\
\hline 3. & Delta & 6 & 13.95 & 10. & Anambra & & 2.33 \\
\hline 4. & FCT & 5 & 11.63 & 11. & Osun & & 2.33 \\
\hline 5. & Enugu & 3 & 6.98 & 12. & Plateau & & 2.33 \\
\hline 6. & C. River & 2 & 4.65 & 13. & Kaduna & & 2.33 \\
\hline 7. & Rivers & 2 & 4.65 & & & & \\
\hline
\end{tabular}

Table 7 shows the distribution of astigmatism according to states in Nigeria.

\section{DISCUSSION}

Our results reveal that out of the total of 864 respondents used for this study, $31.60 \%$ (273) had a refractive error. It means from our results that the incidence of refractive errors among Nigerian youths in tertiary institution stands at $31.60 \%$. This is comparable to $37.39 \%$ reported by Prema, 2011, in a study carried out in India. Our results reveal that North-west region had the highest prevalence of the use of medicated glasses among youths at $61.29 \%$. This is followed by South-west (55.67\%), South-south (36.27\%), South-east (31.67\%), North-central (19.67\%), and North-east (15.79\%).

The incidence of refractive errors according to the different regions of the country shows that North-west had the highest incidence with $61.29 \%$, South-west $50.51 \%$, South-south $32.88 \%$, South-east $27.67 \%$, North-central $18.03 \%$, and North-east $15.79 \%$. This could be associated with the reported high level of poverty and living conditions in this region of the country. It is in line with the report of Feldkamper and Schaeffel (2003) which shows that environmental factors are associated with the frequency of refractive errors.

The highest occurring refractive error among the six geopolitical regions of Nigeria is myopia (54.21\%), followed by hyperopia $(28.21 \%)$, astigmatism $(15.75 \%)$, and presbyopia $(1.83 \%)$. This is similar to the report of Adeoti and Egbewale, 2008, in a study carried out in Ado ekiti where myopia constituted $39.33 \%$, hyermetropia $23.33 \%$, and astigmatism $21.80 \%$. The increasing incidence of refractive errors and consequent use of medicated glasses may be associated with the longer time our youth spend reading books, working on the computer, and watch television according to the report of Prema (2011). This may explain why the incidence was higher in more developed cities and states of the country than the less developed places. Our study population is undergraduates in one of Nigeria's foremost private university. This population has no difficulty with access to eye clinic or basic medical treatment. South-east and South-south had the highest frequency of myopia. These regions are among the most urbanized in the country. This is in line with the previous works that show a positive correlation between myopia and urbanization/industrialization [10].

\section{CONCLUSION}

Our results suggest that there is a rise in the incidence of refractive errors among our youths, leading to increase in the use of medicated glasses, a phenomenon that was more common among the elderly in our society.

\section{Recommendation}

- We, therefore, recommend that government and its agencies should pay attention to those environmental factors that predispose our youths to visual impairments.

- This study can be extended to specific regions of the country, especially those with observed high incidence from this study.

- Furthermore, attention should be paid to sexual disparity in the manifestation of these refractive errors.

\section{REFERENCES}

1. Adeoti CO, Egbewale BE. Refractive errors in Mercyland specialist hospital, Osogbo, Western Nigeria. Niger Postgrad Med J 2008;15:116-9.

2. Dandona R, Dandona L, Naduvilath TJ, Srinivas M, McCarty CA, Rao GN. Refractive errors in an urban population in Southern India: The Andhra Pradesh eye disease study. Invest Ophthalmol Vis Sci 1999;40:2810-8.

3. Prema N. Causing factors of refractive error in children: Heredity or environment. Indian J Sci Technol 2011;4:

4. Holden BA, Sulaiman S, Knox K. The challenge of providing spectacles 
in the developing world. J Community Eye Health 2000;13:9-10.

5. National Committee for Prevention of Blindness. National Programme for Prevention of Blindness: First Five Year Plan. Islamabad, Pakistan National Committee for Prevention of Blindness, Ministry of Health, Special Education and Social Welfare; 1994-98. p. 24.

6. Feldkamper M, Schaeffel F. Interactions of genes and environment in myopia. Dev Ophthalmol 2003;37:34-49.

7. Zadnik K, Satariamo WA, Mutti DO, Cheung YY. The effects of parental H/o myopia on children eye size. JAMA 1994;271:1323-7.

8. Zadnik K. The Glenn A. Fry Award Lecture (1995). Myopia development in childhood. Optom Vis Sci 1997;74:603-8.

9. Mutti DO, Mitchell GL, Moeschberger ML, Jones LA, Zadnik K Parental myopia, near work, school achievement, and children's refractive error. Invest Ophthalmol Vis Sci 2002;43:3633-40.

10. Saw SM, Zhang MZ, Hong RZ, Fu ZF, Pang MH, Tan DT. Near-work activity, night lights, and myopia in the Singapore-China study. Arch Ophthalmol 2002;120:620-7.

11. Dunaway D, Berger I. Worldwide Distribution of Visual Refractive Errors and what to Expect at a Particular Location. Presentation to the International Society for Geographic and Epidemiologic Ophthalmology; 2006. p. 1-9.

12. Tebepah T. Pattern of eye diseases in Port Harcout and an oil producing rural community. Niger J Ophthalmol 1995;3:6-8.

13. Ayed T, Sokkah M, Charfi O, El Matri L. Epidemiologic study of refractive errors in schoolchildren in socioeconomically deprived regions in Tunisia. J Fr Ophthalmol 2002;25:712-17.
14. Chuka-Okosa CM. Refractive Errors among students of a postprimary institution in a rural community in South-Eastern Nigeria. West Afr J Med 2005;24:62-5.

15. Curtin BJ. The Myopias: Basic Science and Clinical Management Philadelphia, PA: Harper and Row; 1985. p. 39-59.

16. Mutti DO, Zadnik K. Age-related decreases in the prevalence of myopia: Longitudinal change or cohort effect? Invest Ophthalmol Vis Sci 2000;41:2103-7

17. Saw SM, Gazzard G, Koh D, Farook M, Widjaja D, Lee J, et al Prevalence rates of refractive errors in Sumatra, Indonesia. Invest Ophthalmol Vis Sci 2002;43:3174-80.

18. Raju P, Ramesh SV, Arvind H, George R, Baskaran M, Paul PG, et al Prevalence of refractive errors in a rural South Indian population. Invest Ophthalmol Vis Sci 2004;45:4268-72.

19. Adegbehingbe BO, Majekodunmi AA, Akinsola FB, Soetan EO Pattern of refractive errors at Obafemi Awolowo University Teaching Hospital, Ile-Ife, Nigeria. Niger J Ophthalmol 2003;11:76-9.

20. Faderin MA, Ajaiyeoba AI. Refractive errors in primary school children in Nigeria. Niger J Ophthalmol 2001;9:10-4.

21. Montes-Mico R, Ferrer-Blasco T. Distribution of refractive errors in Spain. Doc Ophthalmol 2000;101:25-33.

22. Kawuma M, Mayeku R. A survey of the prevalence of refractive errors among children in lower primary schools in Kampala District. Afr Health Sci 2002;2:69-72.

23. Askira BH, Akobundu MN. Refractive errors in Maiduguri. BOMJ 2006;3:7-9.

\section{APPENDIX}

Questionnaire

This research work is been carried out in Madonna University, Elele campus on FREQUENCY OF REFRACTIVE ERRORS AND USE OF MEDICATED GLASSES AMONG NIGERIA YOUTHS. Please kindly respond to the questions as genuinely as possible. Be assured that your confidentiality shall be respected. As the information given cannot be traced to you in any way. All information are strictly for research purposes. Thank you for your cooperation

Section A: Personal information (please tick the appropriate box).

1. Sex: $M$

F

2. Age: $15-20$

21-25

26-30

31-35

3. State of origin

4. Where have you resided for the most part of your life?
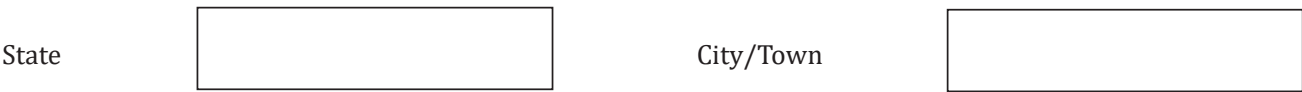

5. For how long have you or did you stay there?

Section B:

1. Do you use glasses? Yes $\square$ No

2. Are your glasses medicated? Yes $\square$ No

3. Please specify the type.

A. Myopia (short-sightedness)

B. Hypermetropia (long-sightedness)

C. Presbyopia

D. Astigmatism

E. Others (please specify)

4. How long have you used it?

5. How many siblings do you have?

6. How many of them use glasses? 